\title{
Teaching behaviors in the cardiac surgery simulation environment
}

\author{
James I. Fann, MD, ${ }^{a}$ Maura E. Sullivan, $\mathrm{PhD},{ }^{\mathrm{b}}$ Kelley M. Skeff, MD, PhD, ${ }^{\mathrm{a}}$ Georgette A. Stratos, $\mathrm{PhD},{ }^{\mathrm{a}}$ \\ Jennifer D. Walker, MD, ${ }^{\mathrm{c}}$ Eugene A. Grossi, MD, ${ }^{\mathrm{d}}$ Edward D. Verrier, MD, ${ }^{\mathrm{e}}$ George L. Hicks, Jr, MD, ${ }^{\mathrm{f}}$ and \\ Richard H. Feins, MD ${ }^{\mathrm{g}}$
}

Objective: To understand how teaching behaviors contribute to simulation-based learning, we used a 7-category educational framework to assess the teaching behaviors used in basic skills training.

\begin{abstract}
Methods: Twenty-four first-year cardiothoracic surgery residents and 20 faculty participated in the Boot Camp vessel anastomosis sessions. A portable chest model with synthetic graft and target vessels and a tissue-based porcine model simulated coronary artery anastomosis. After each 2-hour session on days 1 and 2, residents assessed teaching behaviors of faculty using a 20-item questionnaire based on the 5-point Likert scale. After session on day 1 , faculty completed a self-assessment questionnaire. At 3 months, faculty completed selfassessment questionnaires regarding teaching behaviors in simulation and clinical settings. Each questionnaire item represents 1 or more teaching categories: "learning climate," "control of session," "communication of goals," "promoting understanding and retention," "evaluation," "feedback," and "self-directed learning."
\end{abstract}

Results: Generally, resident ratings indicated that faculty showed positive teaching behaviors. Faculty selfassessment ratings were all lower $(P<.025)$ than those assigned to them by the residents except for 1 component representative of "feedback," which approached significance $(P=.04) ; 2$ items, representative of "promoting understanding and retention" and "evaluation", had mean scores of less than 3. At 3 months, compared with self-assessment at Boot Camp, faculty ratings suggested improved teaching behaviors in their simulation settings in the following: "learning climate," "control of session," "communication of goals," "promoting understanding and retention," and "evaluation." The simulation environment was perceived as more positive for technical skills training in certain aspects compared with clinical setting: instructor reviewed function and operation of equipment with learner before session (representative of "promoting understanding and retention") and instructor allowed the learner ample time to practice (representative of "control of session" and "promoting understanding and retention") $(P<.025)$.

Conclusions: Simulation-based skills training is perceived by residents to be associated with positive teaching behaviors. Faculty self-ratings indicate that they do not always use many of these teaching behaviors and that their performance can be improved. The simulation setting may provide greater opportunity for positive teaching behaviors compared with the clinical environment. (J Thorac Cardiovasc Surg 2013;145:45-53)

Surgical residency education can be complex and difficult. Attending surgeons often must teach residents and fellows who are at various levels of training, requiring a variety of

From Stanford University, ${ }^{a}$ Stanford, Calif; University of Southern California, ${ }^{\mathrm{b}}$ Los Angeles, Calif; Massachusetts General Hospital, ${ }^{\mathrm{c}}$ Boston, Mass; New York University, ${ }^{\mathrm{d}}$ New York, NY; University of Washington, ${ }^{\mathrm{e}}$ Seattle, Wash; University of Rochester, ${ }^{\mathrm{f}}$ Rochester, NY; and University of North Carolina, ${ }^{\mathrm{g}}$ Chapel Hill, NC.

This study was supported by the Thoracic Surgery Directors Association and the Joint Council for Thoracic Surgery Education and grant support from the Thoracic Surgery Foundation for Research and Education (to J.I.F. and R.H.F.), Western Thoracic Surgical Association Doty Award (to J.I.F.), and Stanford Center for Immersive and Simulation-Based Learning (to J.I.F.). Corporate sponsors of this session included the Chamberlain Group, Sorin Group, Cryolife, Inc, and Teleflex Medical.

Disclosures: Authors have nothing to disclose with regard to commercial support.

Received for publication March 9, 2012; revisions received May 25, 2012; accepted for publication July 30, 2012; available ahead of print Oct 24, 2012.

Address for reprints: James I. Fann, MD, Department of Cardiothoracic Surgery, Stanford University, 300 Pasteur Dr, Stanford, CA 94305 (E-mail: jfann@ stanford.edu).

0022-5223/\$0.00

Published by Elsevier Inc. on behalf of The American Association for Thoracic Surgery

http://dx.doi.org/10.1016/j.jtcvs.2012.07.111 methods from psychomotor training intraoperatively to patient management in the intensive care unit and on the ward. Although the expectation of educators is to teach residents in the knowledge, skills, and attitudes necessary to deliver quality health care, the focus on patient care may, by necessity, divert faculty from teaching. ${ }^{1-5}$ In general, medical faculty consider teaching to be an important aspect of their role, and many express a strong desire to improve their teaching, but barriers to effective teaching exist, including faculty motivations and attitudes regarding teaching, degree of institutional support, and lack of protected time to participate in faculty development. ${ }^{1-8}$ To improve the process of teaching in surgery, major organizations have established faculty development programs, such the Surgeons as Educators course by the American College of Surgeons ${ }^{9}$ and the Educate the Educator course by the Joint Council on Thoracic Surgery Education. ${ }^{10,11}$

Over the years, educators have created methods to assist medical faculty in analyzing and improving the teaching 
process. ${ }^{1-8}$ Skeff and Stratos ${ }^{1-8,12}$ at the Stanford Faculty Development Center for Medical Teachers have developed a framework consisting of 7 key categories of teaching, the purpose of which is to encourage teacher reflection and to improve the effectiveness of teaching behaviors. The categories include creating a positive learning climate, organizing control of the teaching session, communication of educational goals, promoting understanding and retention, evaluation of the learner, providing feedback, and fostering self-directed learning. In brief, "learning climate" refers to the atmosphere of the teaching environment and reflects the degree of stimulation, enthusiasm, and comfort generated by the teaching process. ${ }^{1,2,7}$ "Control of session" relates to taskmanagement approaches a teacher uses to focus interaction and reflects the teacher's ability to address relevant topics. "Communication of goals" is the process by which the teacher communicates what attitudes, knowledge, and skills should be acquired in the learning process. "Promoting understanding and retention" pertains to teaching methods used, with emphasis on whether they enhance the learners' understanding and retention. "Evaluation" is the process that determines whether the learner is achieving the goals and may include observing and/or questioning. "Feedback" refers to providing information to the learner for the purpose of improving his or her performance. And "promoting selfdirected learning" includes the learner's initiative and how the teacher encourages one to continue learning throughout one's career. ${ }^{1,2,7}$ Although such analysis of teaching behaviors in the specialty of internal medicine has been widely described, ${ }^{1-8}$ behavioral analysis in surgical skills education has been less well documented. ${ }^{13-15}$

As a means to develop simulation-based learning in cardiothoracic surgery and under the auspices of the Thoracic Surgery Directors Association and Joint Council on Thoracic Surgery Education, national efforts have included the "Boot Camp," a 3-day training session for first-year cardiothoracic surgery residents, and recently the "Senior Tour," a program comprising senior cardiothoracic surgical educators, one of whose directives is to review new and ongoing educational efforts. ${ }^{16-18}$ On the basis of novel simulators and focused practice, the educational experience at the Boot Camp has been well received and rated highly by residents. ${ }^{19,20}$ However, it is not clear as to how and which teaching behaviors contribute to the positive nature of the simulation-based learning environment. To understand the types of teaching behaviors at Boot Camp, we used the previously described 7-category analytical framework as the basis to analyze teaching behaviors used in basic skills training and to promote teacher reflection. Further, we addressed whether there are perceived differences in teaching behaviors in the simulation setting compared with the clinical setting and whether knowledge of teaching behaviors may affect one's teaching methods.

\section{METHODS \\ Subjects}

Twenty-four first-year cardiothoracic surgery residents, all having completed general surgery residency training, and 20 cardiac surgery faculty participated in the 3-day Boot Camp at the Friday Center for Continuing Education at the University of North Carolina, Chapel Hill, in July 2011. Residents' previous experience in cardiac surgery was limited to 1 month or less of formal training in adult cardiac surgery. Of the faculty members, each from a different training program in the United States, the mean length of teaching experience was $14.8 \pm$ 12.9 years (range, 1-41 years); in this group were 5 members of the Senior Tour. The types of teaching experience included 17 participants who had taught medical students, general surgery residents, and cardiothoracic surgery residents; 2 whose experience had been limited to cardiothoracic surgery residents; and 1 who had taught medical students and general surgery residents. Six $(27 \%)$ previously participated in faculty development activities, including Educate the Educators course developed by the Joint Council on Thoracic Surgery Education. ${ }^{11}$ Approval was obtained from the Institutional Review Board at the University of North Carolina to review and analyze the information from this educational activity.

\section{Vessel Anastomosis Training}

The simulation room was equipped with lighting, surgical instruments, and supplies. Mounted in the portable chest model (HeartCase; Chamberlain Group, Great Barrington, Mass) were 3- to 4-mm synthetic target vessels; to simulate vein graft for the anastomosis, 3- 4-mm synthetic vessels and 5-0 and 6-0 polypropylene sutures were used (Figure 1). For the tissuebased model, explanted pig hearts were prepared and supported in a container obtained from WetLab, Ltd (WetLab Station; Kenilworth, Warwicks, United Kingdom). The porcine model provided the following tasks: exposing the left anterior descending artery, arteriotomy, distal end-to-side anastomosis, and proximal graft-to-aorta anastomosis. Expired cryopreserved saphenous veins (Cryolife, Inc, Kennesaw, Ga) were obtained to use as grafts for the anastomosis using the porcine model.

\section{Study Protocol}

Twenty-four residents were assigned to groups of 6 participating in 4 focused sessions including (1) vessel anastomosis, (2) aortic cannulation and cardiopulmonary bypass, (3) bronchoscopy and 1-lung ventilation, and (4) hilar dissection and pulmonary resection. Each session was 2 hours in length on day 1 and day 2 to promote distributed practice. For this study, teaching behaviors were evaluated during the vessel anastomosis session only. Before the skills portion on day 1 , residents were given a 20 minute lecture on coronary anatomy, angiographic evaluation, and techniques for performing end-to-side coronary anastomoses. For each session, the same faculty member was assigned to each resident providing 1-to-1 teaching for both days. At the completion of each 2-hour session, each resident assessed teaching behaviors of the assigned faculty member using a questionnaire. After completion of all sessions on day 1, the faculty met as a group to evaluate the simulation exercises. During this program review period, the faculty completed a self-assessment questionnaire regarding their teaching behaviors in the vessel anastomosis session. Because the study was to assess the existing teaching behaviors in the simulation environment, the faculty were not initially provided with any information regarding the items on the questionnaire. On day 2, residents again participated in the 2-hour vessel anastomosis session with their assigned faculty in the same manner as on day 1 . At the end of the session on day 2, each resident completed a follow-up questionnaire to assess faculty teaching behaviors. At 3 months, the faculty completed self-assessment questionnaires regarding their teaching behaviors in simulation and clinical settings at their institutions. Because the Senior Tour members $(n=5)$ had variable access to simulation and clinical teaching and 3 faculty members 

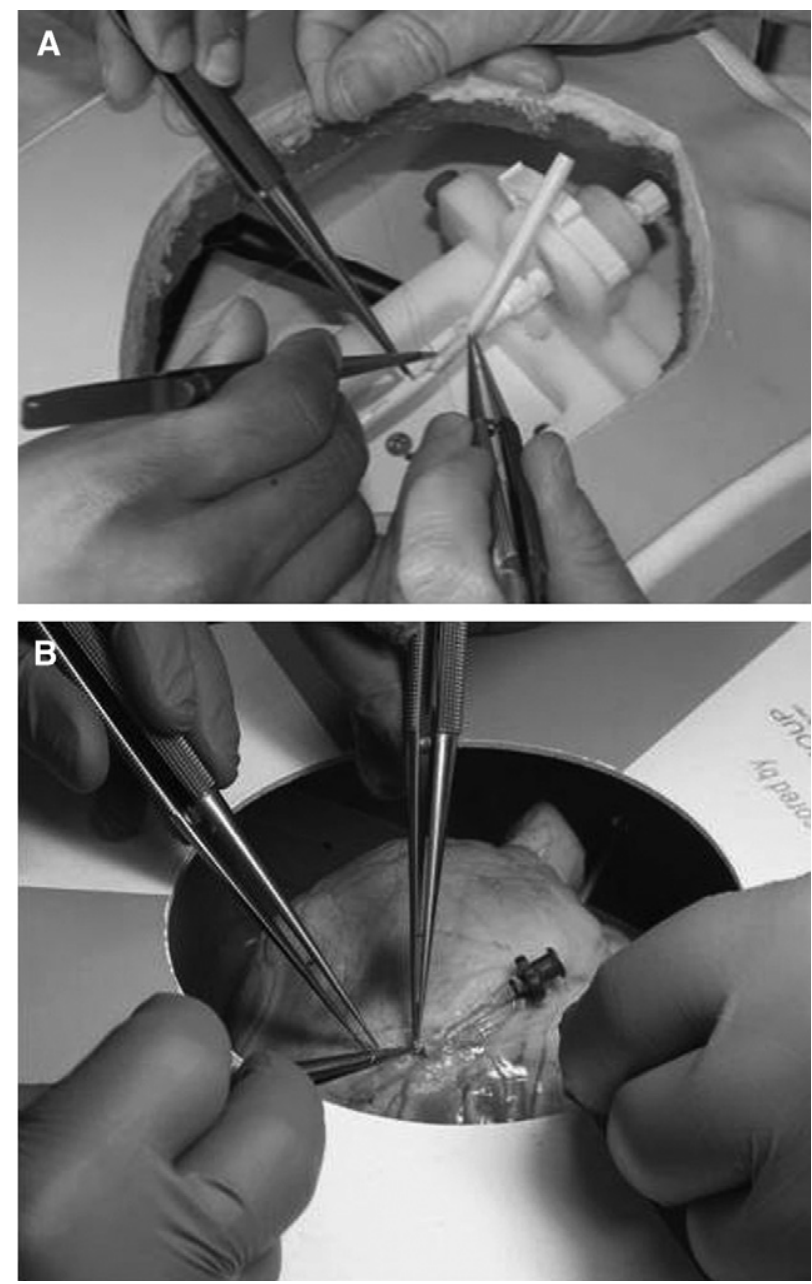

FIGURE 1. A, Mounted in the portable chest model are synthetic target vessels; to simulate coronary anastomosis, synthetic vessels are used. B, For the tissue-based or "wet-lab" component, porcine hearts are prepared and positioned in a container so as to expose the left anterior descending artery. Expired cryopreserved saphenous veins are used as grafts for the anastomosis.

did not participate in simulation locally, they were excluded from the follow-up survey.

\section{Teacher Evaluation Questionnaire}

After the vessel anastomosis sessions on day 1 and day 2, each resident evaluated the teaching behaviors of the assigned faculty using a 20-item questionnaire based on a 5-point Likert scale ( $1=$ strongly disagree; $3=$ neutral; $5=$ strongly agree) (Table 1 ). Each item in this questionnaire was selected to evaluate specific teaching behaviors related to 1 or more of the 7 teaching categories previously described (Table 2).

\section{Teacher Self-Assessment Questionnaire}

Each faculty completed a questionnaire after the first session on day 1 during the program review period (Table 3 ). The self-assessment questionnaire used by faculty to reflect on their teaching behaviors was similar to that used by residents to evaluate faculty. It included 21 items assessing the 7 categories of the medical teaching framework (Table 2) based on a 5-point Likert scale.

\section{Teacher Self-Assessment Questionnaire at 3 Months}

To assess teaching behaviors in the simulation and clinical settings and to obtain follow-up, each faculty completed a questionnaire at 3 months after the completion of Boot Camp. This questionnaire, identical to the previous self-assessment questionnaire, was used by faculty to assess their teaching behaviors in the simulation laboratory and the clinical setting. This questionnaire comprised 21 items assessing the 7 teaching categories as described.

\section{Data Analysis}

The data are reported as mean \pm standard deviation. Paired $t$ tests were used to compare the resident evaluations of faculty teaching behaviors on day 1 with those on day 2. Resident evaluations of teaching behaviors on day 1 were also compared with faculty self-assessments of teaching behaviors using paired $t$ tests. Paired $t$ tests were used to compare faculty self-assessments of teaching at Boot Camp with those in the simulation environment at 3 months. Finally, paired $t$ tests were used to compare faculty self-assessments of teaching in the simulation environment with those in the clinical setting at 3 months. For multiple comparisons, Bonferroni correction was used.

\section{RESULTS}

\section{Teacher Evaluation Questionnaire}

Residents evaluated faculty teaching behaviors on day 1 and day 2 using the 20-item questionnaire; the scores ranged from 3 to 5 with a predominant score of 5 in both sessions. Generally, resident perception was that faculty in the sessions demonstrated teaching behaviors that are considered positive. One item, whether instructors asked for a description of the steps of the procedure from the learner (representative of "evaluation"), was higher on day 2 compared with day $1(P=.03)$ (Table 4$)$. Also, other educational categories were notable for their trends demonstrating slight improvement on day 2, although not statistically significant: instructor providing conceptualization of procedure ("communication of goals" and "promoting understanding and retention"), goals of session were established ("communication of goals"), instructor offered suggestions for improvement ("feedback"), and instructor encouraged further learning ("self-directed learning").

\section{Teacher Self-Assessment Questionnaire}

To provide a self-assessment of teaching behaviors, each faculty completed a questionnaire after the session on day 1 . Faculty self-assessment ratings were all significantly lower than those assigned to them by residents except for instructor provided specific feedback ("feedback"), which approached significance $(P=.04)$ (Table 4$)$. The range of scores was between 1 and 5; however, there were 2 items with mean scores less than 3: instructor demonstrated the entire skill to learner at beginning of session ("promoting understanding and retention") and instructor asked for a description of steps of procedure from learner ("evaluation").

\section{Teacher Self-Assessment Questionnaire at 3 Months}

This self-assessment questionnaire focused on behaviors in both the simulation laboratory and the clinical setting; of 
TABLE 1. Teacher evaluation questionnaire completed by residents after sessions on day 1 and day 2

\begin{tabular}{|c|c|c|c|c|c|}
\hline \multirow[b]{2}{*}{ Please rate the following items } & \multicolumn{5}{|c|}{ Rater: Teaching behavior questionnaire } \\
\hline & $\begin{array}{l}\text { Strongly } \\
\text { disagree }\end{array}$ & Disagree & Neutral & Agree & $\begin{array}{c}\begin{array}{c}\text { Strongly } \\
\text { agree }\end{array} \\
\text { a }\end{array}$ \\
\hline $\begin{array}{l}\text { The instructor demonstrated competency throughout the procedure (was familiar with all } \\
\text { equipment, was knowledgeable about procedure) }\end{array}$ & 1 & 2 & 3 & 4 & 5 \\
\hline $\begin{array}{l}\text { The instructor identified the skills level of the learner (asked about prior performance, graduate } \\
\text { level, and/or prior rotations) }\end{array}$ & 1 & 2 & 3 & 4 & 5 \\
\hline $\begin{array}{l}\text { The instructor provided conceptualization of the procedure (reviewed indications, } \\
\text { contraindications, common errors, potential complications) }\end{array}$ & 1 & 2 & 3 & 4 & 5 \\
\hline The goals of the session were established (clearly and concisely stated) & 1 & 2 & 3 & 4 & 5 \\
\hline The importance of the session was established (relevance of goals to learner was explained) & 1 & 2 & 3 & 4 & 5 \\
\hline The instructor established the expected level of skill performance & 1 & 2 & 3 & 4 & 5 \\
\hline The instructor reviewed the pertinent anatomy with the learner & 1 & 2 & 3 & 4 & 5 \\
\hline The instructor demonstrated the entire skill to the learner at the beginning of the session & 1 & 2 & 3 & 4 & 5 \\
\hline The instructor provided a narration of the steps of the procedure & 1 & 2 & 3 & 4 & 5 \\
\hline The instructor asked for a description of the steps of the procedure from the learner & 1 & 2 & 3 & 4 & 5 \\
\hline The instructor allowed the learner ample time to practice (did not rush, demonstrated patience) & 1 & 2 & 3 & 4 & 5 \\
\hline The instructor provided specific feedback (not vague, gave specifics) & 1 & 2 & 3 & 4 & 5 \\
\hline The instructor debriefed the learner after the session & 1 & 2 & 3 & 4 & 5 \\
\hline The instructor demonstrated enthusiasm & 1 & 2 & 3 & 4 & 5 \\
\hline The instructor demonstrated respect for the learner (did not intimidate, ridicule or interrupt) & 1 & 2 & 3 & 4 & 5 \\
\hline The instructor acknowledged learner limitations & 1 & 2 & 3 & 4 & 5 \\
\hline The teaching session was focused (avoided digressions) & 1 & 2 & 3 & 4 & 5 \\
\hline The instructor clearly stated what was done correctly and incorrectly & 1 & 2 & 3 & 4 & 5 \\
\hline The instructor offered suggestions for improvement & 1 & 2 & 3 & 4 & 5 \\
\hline The instructor encouraged further learning & 1 & 2 & 3 & 4 & 5 \\
\hline
\end{tabular}

those surveyed, all 12 faculty, who currently participate in teaching in simulation and clinical settings, responded (Table 5). Compared with self-assessment at Boot Camp, self-assessment at 3 months showed higher scores in teaching behaviors in the simulation setting. Higher scores were noted in the following: instructor-demonstrated competency ("communication of goals" and "promoting understanding and retention"), goals of session were

TABLE 2. Teaching behavior questionnaire items and their correlate with the 7 categories in the educational framework

\section{Item}

Instructor demonstrated competency throughout procedure

Instructor identified skills level of learner

Instructor provided conceptualization of procedure

Goals of session were established

Importance of session was established

Instructor established expected level of skill performance

Instructor reviewed function and operation of equipment with learner prior to session

Instructor reviewed the pertinent anatomy with learner

Instructor demonstrated the entire skill to learner at the beginning of session

Instructor provided a narration of steps of procedure

Instructor asked for a description of steps of procedure from learner

Instructor allowed the learner ample time to practice

Instructor provided specific feedback

Instructor debriefed learner after session

Instructor demonstrated enthusiasm

Instructor demonstrated respect for learner

Instructor acknowledged learner limitations

Teaching session was focused

Instructor clearly stated what was done correctly and incorrectly

Instructor offered suggestions for improvement

Instructor encouraged further learning

\section{Educational categories}

Communication of goals; promoting understanding and retention Evaluation

Communication of goals; promoting understanding and retention Communication of goals

Learning climate; communication of goals

Communication of goals

Communication of goals; promoting understanding and retention

Promoting understanding and retention

Promoting understanding and retention

Promoting understanding and retention

Evaluation

Control of session; promoting understanding and retention

Feedback

Evaluation

Learning climate

Learning climate

Learning climate

Control of session

Feedback

Feedback

Promoting self-directed learning 
TABLE 3. Teacher self-assessment questionnaire completed after session on day 1

Faculty Teaching Questionnaire

1. Please enter your initials and institution

2. How many years have you been teaching?

3. What level of learners do you teach? (please check all that apply)

- Medical students

- General Surgical Residents

- CT Surgery Residents/Fellows

- Junior faculty

4. Please rate your perceived teaching effectiveness

$$
\begin{aligned}
& \text { - Excellent } \\
& \text { - Good } \\
& \text { - Average } \\
& \text { - Below average } \\
& \text { - Poor }
\end{aligned}
$$

5. Have you ever taken any formal training courses to improve your teaching skills?

$$
\text { YES__ NO }
$$

6. If you answered YES above please describe the course

\section{Please rate the following items:}

I was familiar with the procedure and equipment prior to the session

I identified the skill level of the learner at the beginning of the session (asked about prior performance, graduate level and/or prior rotations)

I reviewed indications, contraindications, common errors and potential complications of the skill prior to session

I stated the goals of the session clearly and concisely

I stated the relevance of the goals of the session to the learner

I stated the expected level of performance for the skill taught in that session

I reviewed function and operation of the equipment with the learner prior to the session

I reviewed the pertinent anatomy with the learner prior to the session

I demonstrated the skill in entirety to provide a model of expected performance at the beginning of

$\begin{array}{ccc}\text { Strongly } & \text { Disagree } & \text { Ne } \\ 1 & 2 \\ 1 & 2 \\ & & \\ 1 & 2 \\ & & \\ 1 & 2 \\ 1 & 2 \\ 1 & 2 & 3 \\ 1 & 2 & 3 \\ 1 & 2 & \\ 1 & 2\end{array}$

the session

I provided a narration of the steps of the procedure at the beginning of the session

I asked the learner to correctly describe the steps of the procedure prior to the session

I allowed the learner ample time to practice

I provided specific feedback

I provided a debriefing session after the practice period

I showed enthusiasm during the session

I demonstrated respect for the learner during each session

I acknowledged learner's limitations

My teaching session was focused

I clearly explained to the learner what was done correctly and incorrectly

I offered the learner suggestions for improvement

I explicitly encouraged further learning

\begin{tabular}{lllll}
1 & 2 & 3 & 4 & 5 \\
1 & 2 & 3 & 4 & 5 \\
1 & 2 & 3 & 4 & 5 \\
1 & 2 & 3 & 4 & 5 \\
1 & 2 & 3 & 4 & 5 \\
1 & 2 & 3 & 4 & 5 \\
1 & 2 & 3 & 4 & 5 \\
1 & 2 & 3 & 4 & 5 \\
1 & 2 & 3 & 4 & 5 \\
1 & 2 & 3 & 4 & 5 \\
1 & 2 & 3 & 4 & 5 \\
1 & 2 & 3 & 4 & 5 \\
\hline
\end{tabular}

established ("communication of goals"), importance of session was established ("learning climate" and "communication of goals"), instructor established level of skill performance ("communication of goals"), instructor reviewed the pertinent anatomy ("promoting understanding and retention"), instructor demonstrated the entire skill to learner at the beginning of session ("promoting understanding and retention"), instructor asked for description of steps of procedure from learner ("evaluation"), and instructor allowed the learner ample time practice ("control of session" and "promoting understanding and retention").

Additionally, the simulation environment generally was perceived as more positive for technical skills training in certain aspects compared with the clinical setting 
TABLE 4. Residents' evaluation of teaching $(n=24)$ and teachers' self-assessment of teaching $(n=20)$

\begin{tabular}{|c|c|c|c|c|c|}
\hline Item & $\begin{array}{c}\text { Resident } \\
\text { assessment } \\
\text { (day 1) } \\
\end{array}$ & $\begin{array}{c}\text { Resident } \\
\text { assessment } \\
\text { (day 2) } \\
\end{array}$ & $\begin{array}{c}P \text { value* } \\
\text { (day } 1 \text { vs day } 2) \\
\end{array}$ & $\begin{array}{c}\text { Teacher } \\
\text { self-assessment }\end{array}$ & $\begin{array}{c}P \text { value* (resident } \\
\text { assessment day } 1 \text { vs } \\
\text { teacher self-assessment) }\end{array}$ \\
\hline $\begin{array}{l}\text { Instructor demonstrated competency throughout } \\
\text { procedure }\end{array}$ & $4.88 \pm 0.45$ & $4.96 \pm 0.21$ & .33 & $4.05 \pm 0.83$ & $<.001$ \\
\hline Instructor identified skills level of learner & $4.83 \pm 0.38$ & $4.87 \pm 0.34$ & .58 & $4.15 \pm 0.93$ & $<.001$ \\
\hline Instructor provided conceptualization of procedure & $4.75 \pm 0.53$ & $4.91 \pm 0.29$ & .06 & $3.65 \pm 0.93$ & $<.001$ \\
\hline Goals of session were established & $4.83 \pm 0.48$ & $4.96 \pm 0.21$ & .08 & $3.35 \pm 0.93$ & $<.001$ \\
\hline Importance of session was established & $4.88 \pm 0.34$ & $4.91 \pm 0.29$ & .16 & $3.5 \pm 1.10$ & $<.001$ \\
\hline Instructor established expected level of skill performance & $4.71 \pm 0.75$ & $4.87 \pm 0.34$ & .16 & $3.45 \pm 1.00$ & $<.001$ \\
\hline Instructor reviewed the pertinent anatomy with learner & $4.88 \pm 0.34$ & $4.96 \pm 0.21$ & .33 & $3.70 \pm 0.98$ & $<.001$ \\
\hline $\begin{array}{l}\text { Instructor demonstrated the entire skill to learner at the } \\
\text { beginning of session }\end{array}$ & $4.75 \pm 0.68$ & $4.87 \pm 0.34$ & .10 & $2.50 \pm 1.19$ & .001 \\
\hline Instructor provided a narration of steps of procedure & $4.88 \pm 0.45$ & $4.96 \pm 0.21$ & .16 & $3.75 \pm 1.25$ & .003 \\
\hline Instructor allowed the learner ample time to practice & $5.00 \pm 0.00$ & $5.00 \pm 0.00$ & 1.00 & $3.40 \pm 1.23$ & $<.001$ \\
\hline Instructor provided specific feedback & $4.88 \pm 0.34$ & $4.91 \pm 0.29$ & .16 & $4.65 \pm 0.49$ & .04 \\
\hline Instructor debriefed learner after session & $4.71 \pm 0.62$ & $4.83 \pm 0.49$ & .16 & $4.10 \pm 0.55$ & .002 \\
\hline Instructor demonstrated enthusiasm & $4.92 \pm 0.28$ & $4.91 \pm 0.29$ & 1.00 & $4.50 \pm 0.51$ & .008 \\
\hline Instructor demonstrated respect for learner & $4.96 \pm 0.20$ & $4.91 \pm 0.42$ & .67 & $4.55 \pm 0.51$ & .008 \\
\hline Instructor acknowledged learner limitations & $4.88 \pm 0.34$ & $4.96 \pm 0.21$ & .33 & $4.15 \pm 0.75$ & $<.001$ \\
\hline Teaching session was focused & $4.96 \pm 0.20$ & $4.96 \pm 0.21$ & 1.00 & $4.45 \pm 0.51$ & $<.001$ \\
\hline $\begin{array}{l}\text { Instructor clearly stated what was done correctly and } \\
\text { incorrectly }\end{array}$ & $4.88 \pm 0.45$ & $4.96 \pm 0.21$ & .16 & $4.35 \pm 0.59$ & .004 \\
\hline Instructor offered suggestions for improvement & $4.79 \pm 0.51$ & $4.87 \pm 0.46$ & .08 & $4.45 \pm 0.60$ & .01 \\
\hline Instructor encouraged further learning & $4.88 \pm 0.34$ & $4.96 \pm 0.21$ & .08 & $4.25 \pm 1.07$ & .01 \\
\hline
\end{tabular}

Data are expressed as mean \pm standard deviation. $* P<.05$ divided by 2 for Bonferroni correction (or $P<.025$ ) is considered significant.

(Table 6). Significant differences included the following: instructor reviewed function and operation of equipment with learner before session ("communication of goals" and "promoting understanding and retention") and instructor allowed the learner ample time to practice ("control of session" and "promoting understanding and retention"). Teaching session was focused ("control of session") approached significance $(P=.04)$.

\section{DISCUSSION}

Assessing teaching behaviors in surgical education may provide an understanding of the deficiencies of skills training in the clinical environment and help define areas for improvement in education and curriculum design. In this study, residents tend to rate faculty teaching behaviors higher than faculty rate themselves. Simulation-based skills training at Boot Camp is perceived by residents to be associated with positive teaching behaviors; however, faculty ratings indicate that they do not always use many of these teaching behaviors and that their behaviors can be improved. At 3 months after Boot Camp, faculty selfassessment suggests that they are able to implement particular teaching behaviors more effectively and that skills training in a simulation setting provides the educator with greater opportunity for positive teaching behaviors than in the clinical environment.

In this study, the resident generally perceived that the faculty demonstrated positive teaching behaviors on both days
1 and 2. Although questionnaire feedback from trainees is commonly used for teaching assessment, such ratings may be less sensitive to change inasmuch as teachers may receive high pretreatment ratings possibly owing to a "halo effect," thereby leading to a "ceiling effect" that makes it difficult to detect improvement. ${ }^{3,6}$ Additionally, changes in teaching performances might not be dramatic enough to be perceived by the learners, and there might have been insufficient time between the implementation of teaching changes and learner evaluations for the evaluations to reflect those changes. ${ }^{3,6}$ At the Boot Camp, because of the residents' highly positive responses on the questionnaire, the results are consistent with a ceiling effect of the assessment tool. Also, the only intervention that might have affected teaching was the teacher self-assessment at the end of day 1 . Self-assessment may not be an adequate stimulus or guide to change teaching behaviors, indicating that a more formal and extensive faculty development program would be useful. Because of the ceiling effect in resident responses, combining resident feedback along with faculty self-assessment may provide a more effective method of evaluating and improving teaching behaviors in basic skills training.

Faculty tend to rate their own teaching abilities highly and thus may not be aware of their own problems as teachers. Self-ratings in faculty development courses indicate that participants may be unaware of all areas for potential improvement until after training. ${ }^{4,8}$ However, at Boot 
TABLE 5. Teacher self-assessment at Boot Camp and in simulation setting at 3-month follow-up $(\mathbf{n}=\mathbf{1 2})$

\begin{tabular}{|c|c|c|c|}
\hline Item & $\begin{array}{l}\text { Self-assessment } \\
\text { (Boot Camp) }\end{array}$ & $\begin{array}{c}\text { Self-assessment } \\
\text { simulation (at } 3 \text { mo) }\end{array}$ & $\begin{array}{l}P \text { value* (Boot Camp vs } \\
\text { simulation at } 3 \text { mo) }\end{array}$ \\
\hline Instructor demonstrated competency throughout procedure & $4.25 \pm 0.75$ & $5.00 \pm 0$ & .006 \\
\hline Instructor identified skills level of learner & $4.33 \pm 0.89$ & $4.75 \pm 0.62$ & .10 \\
\hline Instructor provided conceptualization of procedure & $4.00 \pm 0.85$ & $4.42 \pm 0.79$ & .27 \\
\hline Goals of session were established & $3.33 \pm 1.1$ & $4.75 \pm 0.45$ & $<.001$ \\
\hline Importance of session was established & $3.58 \pm 1.2$ & $4.67 \pm 0.49$ & .005 \\
\hline Instructor established expected level of skill performance & $3.58 \pm 1.0$ & $4.33 \pm 0.98$ & .01 \\
\hline $\begin{array}{l}\text { Instructor reviewed function and operation of equipment with learner prior to } \\
\text { session }\end{array}$ & $3.58 \pm 1.2$ & $4.50 \pm 0.67$ & .03 \\
\hline Instructor reviewed the pertinent anatomy with learner & $3.58 \pm 1.2$ & $4.50 \pm 0.80$ & .02 \\
\hline Instructor demonstrated the entire skill to learner at the beginning of session & $2.58 \pm 1.2$ & $4.00 \pm 0.74$ & .008 \\
\hline Instructor provided a narration of steps of procedure & $4.25 \pm 0.87$ & $4.50 \pm 0.67$ & .34 \\
\hline Instructor asked for a description of steps of procedure from learner & $2.75 \pm 1.1$ & $4.00 \pm 1.0$ & .02 \\
\hline Instructor allowed the learner ample time to practice & $3.50 \pm 1.2$ & $4.67 \pm 0.65$ & .01 \\
\hline Instructor provided specific feedback & $4.75 \pm 0.45$ & $5.00 \pm 0$ & .08 \\
\hline Instructor debriefed learner after session & $4.33 \pm 0.49$ & $4.58 \pm 0.51$ & .19 \\
\hline Instructor demonstrated enthusiasm & $4.58 \pm 0.51$ & $4.83 \pm 0.39$ & .08 \\
\hline Instructor demonstrated respect for learner & $4.48 \pm 0.51$ & $4.92 \pm 0.29$ & .04 \\
\hline Instructor acknowledged learner limitations & $4.58 \pm 0.51$ & $4.83 \pm 0.39$ & .19 \\
\hline Teaching session was focused & $4.58 \pm 0.51$ & $4.92 \pm 0.29$ & .10 \\
\hline Instructor clearly stated what was done correctly and incorrectly & $4.50 \pm 0.52$ & $4.83 \pm 0.39$ & .04 \\
\hline Instructor offered suggestions for improvement & $4.67 \pm 0.49$ & $4.92 \pm 0.29$ & .08 \\
\hline Instructor encouraged further learning & $4.42 \pm 1.0$ & $4.92 \pm 0.29$ & .11 \\
\hline
\end{tabular}

Data are expressed as mean \pm standard deviation. ${ }^{*} P<.05$ divided by 2 for Bonferroni correction (or $P<.025$ ) is considered significant.

Camp, the faculty did not rate themselves highly and identified many areas that were not addressed in their teaching techniques. In particular, low scores were evident in the following: instructor demonstrated the entire skill to learner at beginning of session ("promoting understanding and retention") and instructor asked for a description of steps of procedure from learner ("evaluation"). Teaching related to some of the

TABLE 6. Faculty self-assessment comparing simulation and clinical environments $(n=12)$

\begin{tabular}{|c|c|c|c|}
\hline Item & $\begin{array}{c}\text { Simulation } \\
\text { assessment (3 mo) }\end{array}$ & $\begin{array}{c}\text { Clinical } \\
\text { assessment (3 mo) }\end{array}$ & $* P$ value \\
\hline Instructor demonstrated competency throughout procedure & $5.00 \pm 0$ & $4.92 \pm 0.29$ & .34 \\
\hline Instructor identified skills level of learner & $4.75 \pm 0.62$ & $4.50 \pm 0.67$ & .34 \\
\hline Instructor provided conceptualization of procedure & $4.42 \pm 0.79$ & $3.92 \pm 0.90$ & .08 \\
\hline Goals of session were established & $4.75 \pm 0.45$ & $3.92 \pm 1.2$ & .05 \\
\hline Importance of session was established & $4.67 \pm 0.49$ & $4.42 \pm 0.79$ & .34 \\
\hline $\begin{array}{l}\text { Instructor established expected level of skill performance equipment with learner prior to } \\
\text { session }\end{array}$ & $4.33 \pm 0.98$ & $4.17 \pm 0.94$ & .34 \\
\hline Instructor reviewed function and operation of equipment with learner prior to session & $4.50 \pm 0.67$ & $3.67 \pm 1.2$ & .02 \\
\hline Instructor reviewed the pertinent anatomy with learner & $4.50 \pm 0.80$ & $4.33 \pm 0.98$ & .50 \\
\hline Instructor demonstrated the entire skill to learner at the beginning of session & $4.00 \pm 0.74$ & $4.17 \pm 0.58$ & .50 \\
\hline Instructor provided a narration of steps of procedure & $4.50 \pm 0.67$ & $4.58 \pm 0.67$ & .75 \\
\hline Instructor asked for a description of steps of procedure from learner & $4.00 \pm 1.0$ & $3.92 \pm 1.0$ & .81 \\
\hline Instructor allowed the learner ample time to practice & $4.67 \pm 0.65$ & $3.75 \pm 0.97$ & .01 \\
\hline Instructor provided specific feedback & $5.00 \pm 0$ & $4.92 \pm 0.29$ & .34 \\
\hline Instructor debriefed learner after session & $4.58 \pm 0.51$ & $4.33 \pm 0.78$ & .34 \\
\hline Instructor demonstrated enthusiasm & $4.83 \pm 0.44$ & $4.83 \pm 0.39$ & 1.00 \\
\hline Instructor demonstrated respect for learner & $4.92 \pm 0.29$ & $4.67 \pm 0.65$ & .19 \\
\hline Instructor acknowledged learner limitations & $4.83 \pm 0.39$ & $4.58 \pm 0.51$ & .08 \\
\hline Teaching session was focused & $4.92 \pm 0.29$ & $4.58 \pm 0.67$ & .04 \\
\hline Instructor clearly stated what was done correctly and incorrectly & $4.83 \pm 0.39$ & $4.75 \pm 0.45$ & .59 \\
\hline
\end{tabular}

Data are expressed as mean \pm standard deviation. $* P<.05$ divided by 2 for Bonferroni correction (or $P<.025$ ) is considered significant. 
educational categories seemed to improve on the basis of resident assessment of teaching comparing day 1 with day 2. In addition, faculty appeared to positively modify their behaviors as seen in the comparison of their selfassessments on day 1 at Boot Camp with those at the local institutions at 3-month follow-up. Thus, it appeared that a self-assessment questionnaire in the midst of training may be a positive intervention to achieve some gains in teaching performance.

Often implied in presenting the positive aspects of simulation-based skills training in cardiothoracic surgery has been the notion that educators can spend more time teaching in a less stressful environment ${ }^{16-18,21-25}$; however, it is not clear how simulation specifically affects teaching behaviors. The findings of the follow-up questionnaire at 3 months are consistent with the proposition that teaching behaviors differ in the simulation compared with the operating room environment, particularly in the components of "control of session," "communication of goals," and "promoting understanding and retention." Included in "control of session" are 2 critical components of skills teaching, including allowing the learner ample time to practice and providing focus on teaching. Reviewing function and operation of equipment with learner before the session fits with promoting "communication of goals" and "promoting understanding and retention." Technical skills training in the simulation environment thus may be less stressful because simulation permits time to practice, which is not always possible in the operating room owing to time constraints of beating heart surgery or arrested heart surgery on cardiopulmonary bypass. Simulation provides better "control of session" opportunities because it is an environment that permits the teaching session to be focused; in contrast, the focus in the clinical setting is on patient care, and effective teaching thus may be compromised. Although the clinical setting for cardiac surgical education may be by its nature less conducive to basic skills training, it is critical for learning advanced techniques, situation awareness, and intraoperative judgment. Further studies may reveal ways to enhance the accomplishment of these goals in the clinical setting.

Recognizing that faculty development programs can lead to improved teaching behaviors, potential barriers impede participation in such programs, including the attitudes and misconceptions of teachers and insufficient support from institutions. ${ }^{4-6,8}$ Attitudes of teachers that can diminish the likelihood of participation include a tendency to underestimate the potential benefits from a program and a lack of belief in the utility of teaching skills as opposed to clinical skills. ${ }^{4,5,8}$ Another impediment to participation in these programs is the belief that clinical skills are sufficient for excellent teaching. ${ }^{5,8}$ Some teachers may believe that training is unrelated to excellence and point to the fact that many of the best clinical teachers are untrained. It is our belief that expert teachers not only are knowledgeable but also are able to make the content understandable to the learner. Although many "untrained" teachers are superb, it is important to ask whether they are as good as they could be. ${ }^{5,8}$ As in the Boot Camp and the Joint Council on Thoracic Surgery Education Educate the Educator course, principles of faculty development and of simulation-based learning can assist faculty to identify unrecognized opportunities to improve their teaching. Although the Boot Camp is primarily focused on advancing the skills of trainees, it has served as a means to increase faculty exposure to simulation-based learning in resident education. Importantly, by identifying key educators who are interested in simulation at each institution, the Boot Camp has provided a venue for the advancement of this educational modality. For the past 2 years, concurrent with the annual Boot Camp has been the Joint Council Educate the Educator course, which has trained more than 70 cardiothoracic surgical educators. ${ }^{10,11}$ Thus, faculty development programs will ensure that educators in our specialty will have access to effective educational methods, such as an understanding of teaching behaviors, and that changes in teaching performance can lead to the ultimate goal of improved learning outcomes.

\section{Limitations}

The faculty self-assessment and resident assessment questionnaires of teaching behaviors are subjective, and a more objective evaluation of change in teaching behaviors or learning outcomes would be optimal. It is also possible that teacher responses to the questionnaire items might differ from their actual opinions or behavior; that is, there may be a tendency to give socially desirable answers or the lack of confidentiality may affect the responses. Also, self-assessment in the simulation setting at 3 months may be affected by concomitant selfassessment in the clinical setting. Thus, objective evaluation of teaching behaviors either on-site or by review of video-recordings would provide confirmation of actual improvements in teaching behaviors in technical skills training. The participants were selected because of their interest in teaching and have been identified as the simulation "point persons" at their respective institutions; therefore, it is possible that they were more motivated than the average physician to reflect on their ability to teach. Ultimately, it would be important to demonstrate that positive teaching behaviors lead to better resident performance in technical skills training.

In conclusion, skills training at Boot Camp provides an opportunity to identify positive teaching behaviors and to develop more effective teaching strategies. In addition, ongoing teaching evaluation can elucidate the learning outcome benefits of teaching in both the simulation environment and the clinical setting. Assessing such 
behaviors in surgical education provides a means to define areas for improvement in faculty development and curriculum design.

We thank all the faculty and resident participants of the Boot Camp. We acknowledge Beth Winer, Nancy Puckett, and Joyce Gambino for their assistance in the organization of this program.

\section{References}

1. Skeff KM. The chromosomal analysis of teaching: the search for promoter genes. Trans Am Clinical Climatological Assoc. 2007;118:123-32.

2. Skeff KM. Enhancing teaching effectiveness and vitality in the ambulatory setting. J Gen Intern Med. 1988;3(2 Suppl):S26-33.

3. Skeff KM. Evaluation of a method for improving the teaching performance of attending physicians. Am J Med. 1983;75:465-70.

4. Berman J, Skeff KM. Developing the motivation for improving university teaching. Innov Higher Educ. 1988;12:114-25.

5. DeRosa DA, Skeff K, Friedland JA, Coburn M, Cox S, Pollart S, et al. Barriers to effective teaching. Acad Med. 2011;86:453-9.

6. Skeff KM, Stratos G, Campbell M, Cooke M, Jones HW III. Evaluation of the seminar method to improve clinical teaching. J Gen Intern Med. 1986;1:315-22.

7. Litzelman DK, Stratos GA, Marriott DJ, Skeff KM. Factorial validation of a widely disseminated educational framework for evaluating clinical teachers. Acad Med. 1998;73:688-95.

8. Skeff KM, Stratos GA, Mygdal W, DeWitt TA, Manfred L, Quirk M, et al. Faculty development. A resource for clinical teachers. J Gen Intern Med. 1997; 12(Suppl 2):S56-63.

9. American College of Surgeons. Surgeons as educators course Web page. Available at: http://www.facs.org/education/sre/saeintro.html. Accessed March 9, 2012.

10. Verrier ED. Joint Council on Thoracic Surgical Education: an investment in our future. J Thorac Cardiovasc Surg. 2011;141:318-21.

11. Joint Council on Thoracic Surgery Education. Events Web page. Available at: http://www.jctse.org/events.html. Accessed March 9, 2012.
12. Litzelman DK, Westmoreland GR, Skeff KM, Stratos GA. Student and residen evaluations of faculty: how dependable are they? Acad Med. 1999;74:S25-7.

13. Wetzel CM, Black SA, Hanna GB, Athanasiou T, Kneebone RL, Nestel D, et al. The effects of stress and coping on surgical performance during simulations. Ann Surg. 2010;251:171-6.

14. Chen X, Williams RG, Sanfey HA, Dunnington GL. How do supervising surgeons evaluate guidance provided in the operating room? Am J Surg. 2012; 203:44-8.

15. Rogers DA, Boehler ML, Schwind CJ, Meier AH, Wall JCH, Brenner MJ. Engag ing medical students in the feedback process. Am J Surg. 2012;203:21-5.

16. Fann JI, Calhoon JH, Carpenter AJ, Merrill WH, Brown JW, Poston RS, et al Simulation in coronary artery anastomosis early in residency training: The Boot Camp experience. J Thorac Cardiovasc Surg. 2010;139:275-81.

17. Hicks GL Jr, Gangemi J, Angona RD Jr, Ramphal PS, Feins RH, Fann JI. Cardiopulmonary bypass simulation and assessment at the Boot Camp. J Thorac Cardiovasc Surg. 2011;141:284-92.

18. Fann JI, Feins RH, Hicks GL Jr, Nesbitt J, Hammon J, Crawford F, and members of the Senior Tour in Cardiothoracic Surgery. Evaluation of simulation training in cardiothoracic surgery: the Senior Tour perspective. J Thorac Cardiovasc Surg. In press.

19. Hicks GL Jr, Brown JW, Calhoon JH, Merrill WH. You never know unless you try. J Thorac Cardiovasc Surg. 2008;136:814-5.

20. Feins RH. Expert commentary: cardiothoracic surgical simulation. J Thorac Cardiovasc Surg. 2008;135:485-6.

21. Fann JI, Caffarelli AD, Georgette G, Howard SK, Gaba DM, Youngblood P, et al Improvement in coronary anastomosis with cardiac surgery simulation. J Thorac Cardiovasc Surg. 2008;136:1486-91.

22. Joyce DL, Dhillon TS, Caffarelli AD, Joyce DD, Tsirigotis DN, Burdon TA, et al Simulation and skills training in mitral valve surgery. J Thorac Cardiovasc Surg. 2011;141:107-12.

23. Ramphal PS, Coore DN, Craven MP, Forbes NF, Newman SM, Coye AA, et al. A high fidelity tissue-based cardiac surgical simulator. Eur J Cardiothorac Surg. 2005;27:910-6.

24. Carter YM, Marshall MB. Open lobectomy simulator is an effective tool for teaching thoracic surgical skills. Ann Thorac Surg. 2009;87:1546-50.

25. Tesche LJ, Feins RH, Dedmon MM, Newton KN, Egan TM, Haithcock BE, et al. Simulation experience enhances medical students' interest in cardiothoracic surgery. Ann Thorac Surg. 2010;90:1967-74. 